\title{
Comparative analysis of the complete mitochondrial genome sequences and anther development cytology between maintainer and Ogura-type cytoplasm male-sterile cabbage (B. oleracea Var. capitata)
}

Xionghui Zhong ${ }^{1}$, Denghui Chen ${ }^{1,2}$, Jian Cui ${ }^{1}$, Hailong Li ${ }^{1}$, Yuxin Huang ${ }^{1}$ and Jungen Kang ${ }^{1 *}$

\begin{abstract}
Background: Cytoplasmic male sterility (CMS) has been widely used for commercial F1 hybrid seeds production. CMS is primarily caused by chimeric genes in mitochondrial genomes. However, which specific stages of anther development in cabbage are affected by the chimeric genes remain unclear.

Results: In the present study, the complete mitochondrial genomes were sequenced and assembled for the maintainer and Ogura CMS cabbage lines. The genome size of the maintainer and Ogura CMS cabbage are 219,962 bp and 236,648 bp, respectively. There are 67 and 69 unknown function ORFs identified in the maintainer and Ogura CMS cabbage mitochondrial genomes, respectively. Four orfs, orf102a, orf122b, orf138a and orf154a were specifically identified in the Ogura CMS mitochondrial genome, which were likely generated by recombination with Ogura type radish during breeding process. Among them, ORF138a and ORF154a possessed a transmembrane structure, and orf138a was co-transcribed with the atp8 and trnfM genes. orf154a is partially homologous to the ATP synthase subunit 1 (atpA) gene. Both these genes were likely responsible for the CMS phenotype. In addition, cytological sections showed that the abnormal proliferation of tapetal cells might be the immediate cause of cytoplasmic male-sterility in Ogura CMS cabbage lines. RNA-seq results showed that orf138a and orf154a in Ogura CMS might influence transcript levels of genes in energy metabolic pathways.

Conclusions: The presence of orf138a and orf154a lead to increased of ATPase activity and ATP content by affecting the transcript levels of genes in energy metabolic pathways, which could provide more energy for the abnormal proliferation of tapetal cells. Our data provides new insights into cytoplasmic male-sterility from whole mitochondrial genomes, cytology of anther development and transcriptome data.
\end{abstract}

Keywords: Cytoplasmic male sterility (CMS), orf138a, orf154a, Mitochondrial genome, Tapetal cell

\footnotetext{
* Correspondence: kangjungen@nercv.org

'Beijing Vegetable Research Center, Beijing Academy of Agriculture and Forestry Sciences, Key Laboratory of Biology and Genetic Improvement of Horticultural Crops (North China), Ministry of Agriculture, 100097 Beijing, P.R. China

Full list of author information is available at the end of the article
}

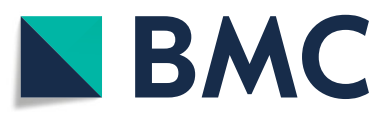

(๑) The Author(s). 2021 Open Access This article is licensed under a Creative Commons Attribution 4.0 International License, which permits use, sharing, adaptation, distribution and reproduction in any medium or format, as long as you give appropriate credit to the original author(s) and the source, provide a link to the Creative Commons licence, and indicate if changes were made. The images or other third party material in this article are included in the article's Creative Commons licence, unless indicated otherwise in a credit line to the material. If material is not included in the article's Creative Commons licence and your intended use is not permitted by statutory regulation or exceeds the permitted use, you will need to obtain permission directly from the copyright holder. To view a copy of this licence, visit http://creativecommons.org/licenses/by/4.0/. The Creative Commons Public Domain Dedication waiver (http://creativecommons.org/publicdomain/zero/1.0/) applies to the data made available in this article, unless otherwise stated in a credit line to the data. 


\section{Background}

Plant male sterility refers to the failed production of normal anthers, pollen and male gametes. Male sterility is an efficient and cost-effective way to utilize heterosis in F1 seed production in many crops, such as corn, rice, wheat, and some species of brassica vegetables. Male sterility is classified into cytoplasmic male sterility (CMS) and genic male sterility (GMS) according to its genetic basis. CMS is caused by the interaction between the cytoplasm and nuclear genes [1]. However, GMS is controlled by nuclear genes alone [2].

The CMS of Brassica oleracea derives from sterile cytoplasm of other cruciferous species, including $B$. rapa, B. nigra, B. napus and Rahanus sativus. The ogu CMS, nap CMS, pol CMS, and hau CMS systems have been studied widely and used practically in Brassica breeding. Ogura CMS was discovered from a wild variety of Japanese radish (R. sativus) [3]. This radish CMS was first transferred into $B$. oleracea through distant hybridization and consecutive backcrossing in 1974 [4]. nap CMS was first found in rapeseed in 1971, and was used for heterosis breeding in 1973 [5, 6]. Polima ( $p o l)$ CMS of B. napus is another well-studied male sterility type, which was transferred into $B$. oleracea by protoplast fusion [7]. hau CMS was first identified in $B$. juncea, and the male sterility was transferred to B. napus by interspecific hybridization [8]. With the development of DNA sequencing technology, more and more mitochondrial and chloroplast genomes of CMS lines have been sequenced completely. Consequently, comparative genomics showed that CMS is caused by rearrangement of the mitochondrial genome. Furthermore, some novel chimeric open reading frames (ORFs) generated by mitochondrial recombination have been reported as the determinants of CMS.

To date, the CMS-specific ORFs could be categorized into three groups : (1) ORFs that are co-transcribed with the adjacent upstream or downstream functional genes ; (2) ORFs located in the unique region of the mitochondrial genome of sterile lines, which are mostly similar to mitochondrial sequences of other species or have no homologous sequence in the known databases; and (3) ORFs possessing a chimeric structure, which have patial homologous sequences to known genes. For example, orf138 has been considered as the determinant of Ogura CMS in Brassiceae [9]. Usually, orf138 is found to be cotranscribed with atp 8 and trnfM [10]. In B. napus, orf 222 is regarded as the master control genes for nap male-sterility. In addition, orf 224 is responsible for pol male-sterile of B.napus and orf 224 is co-transcribed with atp6 [1]. Co-expression of orf 222 with nad5c and orf139 might be the cause of nap CMS [11]. The chimeric CMS-associated gene orf 288 is a CMS-associated gene in the hau CMS line of B. juncea. Moreover, orf 288 possess a partial sequence of nad5 and is co-transcribed with the downstream gene atp6 [12, 13]. The different CMSassociated genes all cause similar phenotypic male sterility in different plants. It is generally agreed that anther-specific gene expression would represent straightforward evidence for CMS; however, none of CMS-associated genes show anther-specific expression, therefore, the interaction of CMS-associated genes with the anther development pathways requires further study.

Therefore, four hypothetical models have been proposed to demonstrate the mechanism of CMS: the cytotoxicity model, the mitochondrial energy deficiency model, the aberrant tapetal programmed cell death (PCD) model, and the retrograde regulation model [14]. For the CMS protein cytotoxicity model, ORF138 and ORF288 proteins have been found to be toxic to E.coli; however, there is lack of direct cytotoxicity evidence in plant anther cells $[13,15,16]$. Mitochondria, as the cell "energy factories", supply ATP to meet the substantial energy requirements of anther development; disorders of mitochondrial functions could have dramatic effects on energy production, which will trigger male sterility. Many studies have reported that some CMS-associated genes are co-transcribed with subunits of the electron transport chain and ATP synthase complexes [1, 10]. This characteristic strongly suggests a link between the energy deficiency hypothesis and CMS. In the aberrant programmed cell death model, tapetum functions in surrounding and nurturing the pollen grains [17] and abnormal (advanced or delayed) tapetal PCD results in the CMS [18-20]. The hypothesis of the retrograde regulation model is based on alteration in nuclear gene expression as a result of signaling from mitochondria to the nucleus, which is induced with genetically or metabolically [21]. For instance, carrot 'carpeloid' CMS is caused by mitochondrial influence on the expression two MADS box genes [22]. Furthermore, the expression level of ORF11 under rice CW cytoplasm determines fertility or CMS, which was also explained using the retrograde signaling model [23].

In the present study, through comparative analysis of the maintainer and Ogura CMS sequenced mitochondrial genomes, we found that the cytoplasm of Ogura CMS was likely generated by recombination with Ogura-type radish during the breeding process. Four orfs (orf102a, orf122b, orf138a and orf154a) from radish were specifically identified in the Ogura CMS mitochondrial genome. orf138a was co-transcribed with atp8 and trnfM. Interestingly, ORF154a also possessed a transmembrane structure and its gene is located between Ogura CMS block 4 and Unique region II. However, which stage of anther development is affected by these chimeric genes remains elusive in cabbage. Our cytological sections data showed that the abnormal proliferation of tapetal cells might be the 
immediate cause of cytoplasmic male-sterility in Ogura CMS cabbage line. RNA sequencing (RNA-seq) results indicated that the transcript levels of genes in energy metabolic pathways in Ogura CMS were affected by mitochondrial recombination. Finally, our data provides new insights into the CMS process through comparative analysis of whole mitochondrial genomes, the cytology of anther development, and transcriptome data.

\section{Results}

\section{Assembly of mitochondrial genome sequences of maintainer and Ogura CMS lines}

The mitochondrial genomes of the maintainer and Ogura CMS cabbage lines were sequenced using Illumina Hiseq and PacBio Sequel techniques. In the Illumina Hiseq data, $8399 \mathrm{Mb}$ and $9036 \mathrm{Mb}$ of raw data were generated from the maintainer and Ogura CMS lines, respectively. We obtained $4983 \mathrm{Mb}$ and $6197 \mathrm{Mb}$ of clean data after filtering out adapters, reads containing over $10 \% \mathrm{Ns}$ and low-quality reads, respectively. The average of the Phred scores (Q20 and Q30) were calculated as over 94.71 and $96.81 \%$ for these two cabbage samples. In the PacBio Sequel data, 96.37 Mb and $196.47 \mathrm{Mb}$ subread bases were produced, the average length of the subreads were 8667 and $8684 \mathrm{bp}$ after filtering the low-quality polymerase reads in the samples of maintainer and Ogura CMS and cabbage lines, respectively. The mitochondrial genomes of the maintainer and Ogura CMS cabbage lines were assembled into a single, circular molecule with sizes of 219,962 bp and 236,648 bp, respectively. The GC contents of mitochondrial genomes were 45.26 and $45.38 \%$, respectively (Figs. 1 and 2). The complete mitochondrial genome sequences of the maintainer and Ogura CMS lines were deposited in the GenBank nucleotide sequence database (https://www.ncbi. nlm.nih.gov/genbank/) under the accession numbers MW423604 and MW423605, respectively.

\section{Comparative analysis of protein-coding genes in the mitochondrial genomes}

We identified 31 known genes, 67 ORFs, 3 rRNA genes (5 S, 18 and $26 \mathrm{~S}$ ), and 25 tRNA genes in the maintainer line genome using BLAST and tRNA-SE (Supplementary Table 1). Mitochondria are known as the cell "powerhouse",

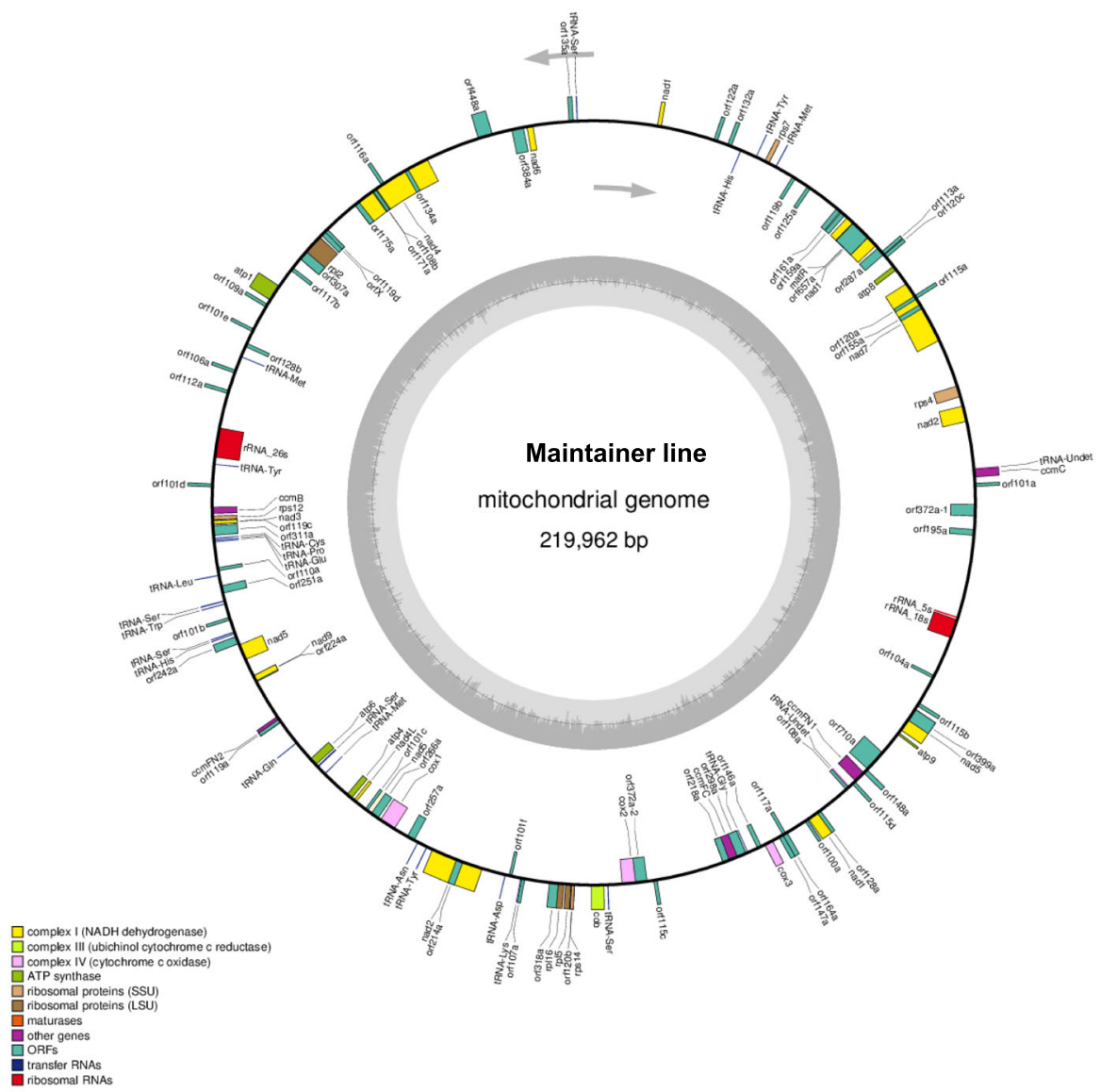

Fig. 1 The mitochondrial genome map of the maintainer line. Genes with names inside the circle are transcribed clockwise. Genes with names outside the circle are transcribed counterclockwise. The colors of the genes denote the functions of the gene products 


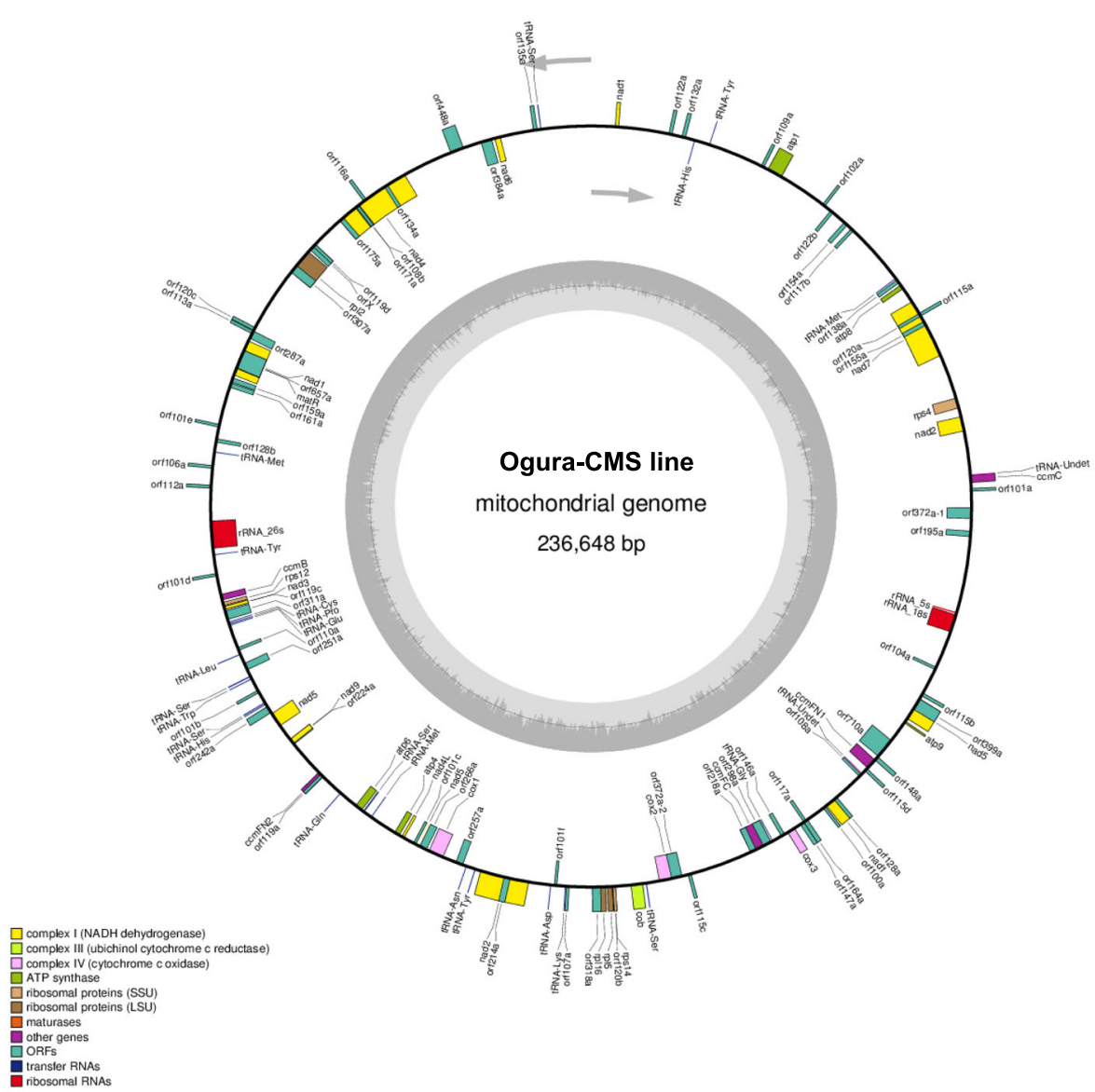

Fig. 2 The mitochondrial genome map of the Ogura CMS line. Genes with names inside the circle are transcribed clockwise. Genes with names outside the circle are transcribed counterclockwise. The colors of the genes denote the functions of the gene products

which supply ATP through oxidative phosphorylation complexes. The 31 known genes are involved the electron transport chain and ATP synthase, such as nine subunits of complex I (nad1, 2, 3, 4, 4L, 5, 6, 7, and 9), one subunit of complex II $(c o b)$, three subunits of complex IV (cox1, 2 and 3) and five subunits of complex V (atp1, 4, 6, 8, and 9). In addition, there were five genes $(\mathrm{ccmB}, \mathrm{ccmC}, \mathrm{ccmFN1}$, $c c m F N 2$ and $c c m F C$ ) that participate in cytochrome c biogenesis, seven ribosomal genes (rpl2, rpl5, rpl16, rps4, rps7, rps12 and rps14) and one maturase gene (matR). By contrast, the mitochondrial genome of the Ogura CMS line possess 30 known genes, 69 ORFs, 3 rRNA genes and 25 tRNA genes (Supplementary Table 2). Interestingly, rps7 was lost in the Ogura CMS mitochondrial genome.

\section{Collinearity analysis of the mitochondrial genomes}

The maintainer and Ogura CMS cabbage mitochondrial genome, together with three published radish Ogura CMS mitochondrial genomes, were subjected to synteny analysis. The collinearity, inversion, translocation and Tran + Inver syntenic blocks were identified in each comparison (Fig. $3 \mathrm{~A}$ to 3D). The syntenic regions shared high sequence similarity between the maintainer and Ogura CMS cabbage mitochondrial genomes. However, the mitochondrial genomes of the Ogura CMS cabbage lines were separated into six syntenic regions by unique regions (Fig. $3 \mathrm{~A}$ and $\mathrm{3E}$ ). The collinearity analysis between Ogura CMS cabbage lines and different radish Ogura CMS lines showed that the unique regions are more likely to have come from the mitochondrial genome of the radish cultivar MS-Gensuke (AB694744) or cultivar Kosena (AP018472) than from cultivar Uchiki-gensuke (AB694743) (Fig. 3B and D). From the details of the collinearity analysis between the maintainer and Ogura CMS cabbage lines, we found six main syntenic regions (named as block 1 to block 6) (Fig. 3E), ranging from 1174 bp to $126,969 \mathrm{bp}$, which accounted for 89.71 and $96.52 \%$ of the mitochondrial genome sequence in the Ogura CMS and maintainer lines, respectively. The corresponding blocks of the maintainer and Ogura CMS lines had at least $99 \%$ identity. Block 1 /block 4 , block 4 /block 5 , block 5 /block 3 , block 5/block 3 and block 2/block 6 in the C5 CMS line 

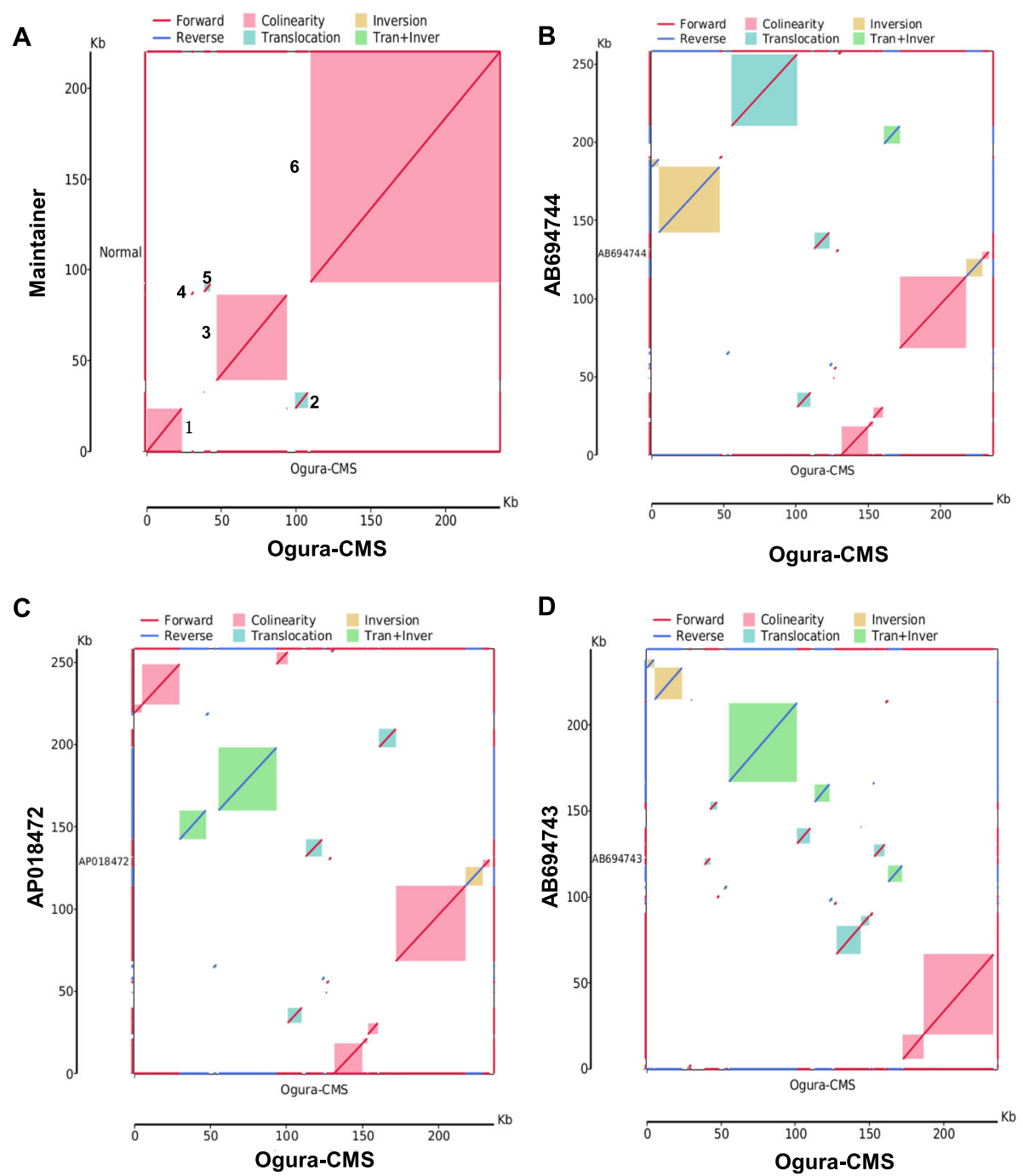

E

Maintainer

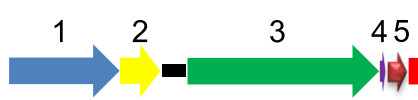

6

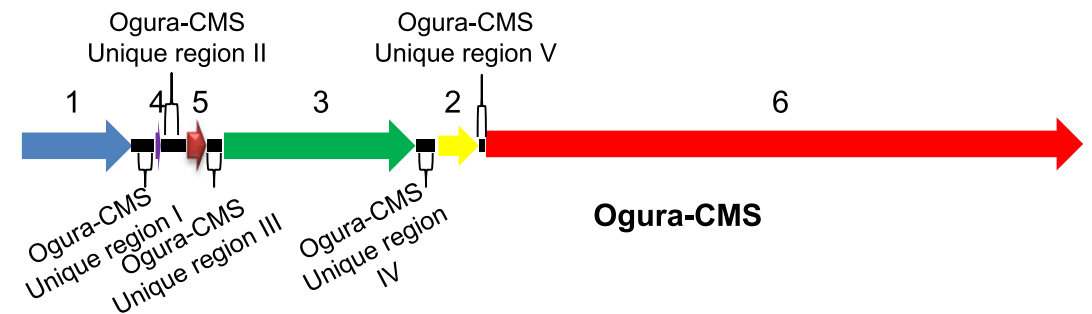

Fig. 3 Collinearity analysis of the mitochondrial genomes. (A) Ogura CMS line genome on the X-axis, plotted against maintainer line genome on the $\mathrm{Y}$-axis. Red lines indicate forward alignment, blue lines indicate reverse alignment. The numbers behind the inner squares for the syntenic regions correspond to those indicated in panel $\mathbf{A}$. The color of the inner bars represent the alignment types; red color: Collinear; green color: Translocation; yellow color: Inversion. (B) to (D) Ogura CMS linear genome on the X-axis, plotted against the radish Ogura CMS cultivars MSGensuke (AB694744), Kosena (AP018472), Uchiki-gensuke (AB694743 ) genomes on the Y-axis. (E) Schematic illustration of six syntenic regions in the mitochondrial genomes of the maintainer and Ogura CMS cabbage lines. Six syntenic regions were named as block 1 to block 6. Ogura CMS had five unique regions 
are broken by unique region I, unique region II, unique region III, unique region IV and unique region $\mathrm{V}$, respectively (Fig. 3E), which means that these regions had undergone recombination during the breeding process. Compared with the maintainer line, the Ogura CMS had three big forward syntenic regions (block 1, block 3 and block 6) and three small translocation syntenic regions (block 2, block 4 and block 5) (Fig. 3E). Our data showed that there had been an extensive recombination and rearrangement in the Ogura CMS cabbage mitochondrial genomes (Fig. 3).

\section{Analysis of the unique regions in the Ogura CMS mitochondrial genomes}

From the collinearity analysis, we found that the Ogura CMS mitochondrial genome has five unique regions that are non-homologous to the maintainer mitochondrial genome (Fig. $3 \mathrm{~A}$ ). The size of unique regions I to $\mathrm{V}$ are $6291 \mathrm{bp}, 7056 \mathrm{bp}, 4225$ bp, 5457 and 1715 bp, respectively. Total length of the unique regions is $25,125 \mathrm{bp}$, which accounts for $10.6 \%$ of the whole Ogura CMS mitochondrial genome. BLASTN searching of nucleotide databases using the unique regions from I to $\mathrm{V}$ showed that the unique sequences have high similarity with mitochondrial sequences of radish cultivar MSGensuke (AB694744) or cultivar Kosena (AP018472). Ogura CMS unique region I has higher similarity with sequence of AB694744 (99.97\%) than that of AP018472 $(99.95 \%)$ (Fig. $4 \mathrm{~A}$ and $4 \mathrm{~B})$. The unique regions I to $\mathrm{V}$ were located at position $159,703 \mathrm{bp}-165,993 \mathrm{bp}$, 151,092 bp-158,147 bp, 142,688 bp-146,912 bp, 249,243 bp-254,699 bp and 37,956 bp-39,670 bp of mitochondrial sequences of MS-Gensuke, respectively. Specific ORFs only appeared in unique regions I and II. orf $102 a$ and orf $122 b$ were located in the Ogura CMS unique region II, and orf138a was located at the left edge of the Ogura CMS unique region I (Table 1; Fig. 4 A); however, orf154a was located between Ogura CMS block

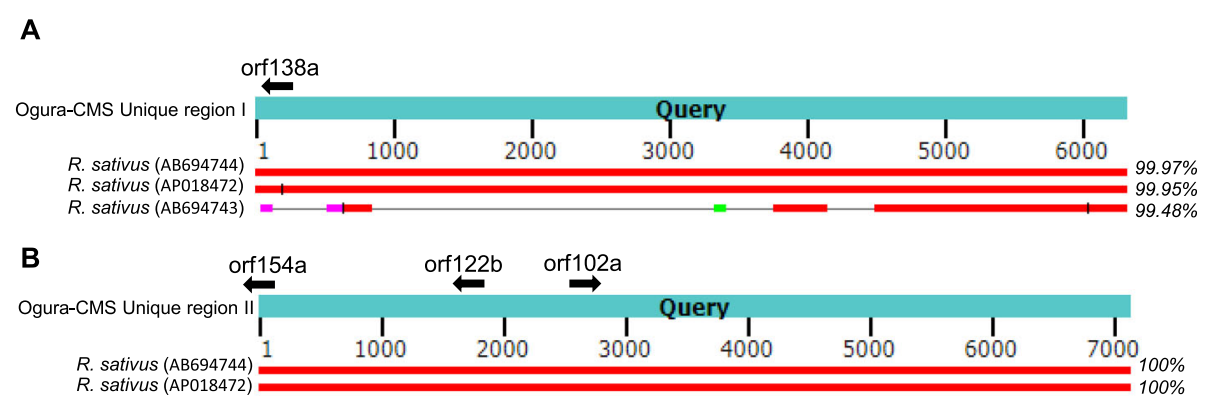

C AB055443.1 R.sativus mitochondrial gene orf138 haplotype:I complete cds

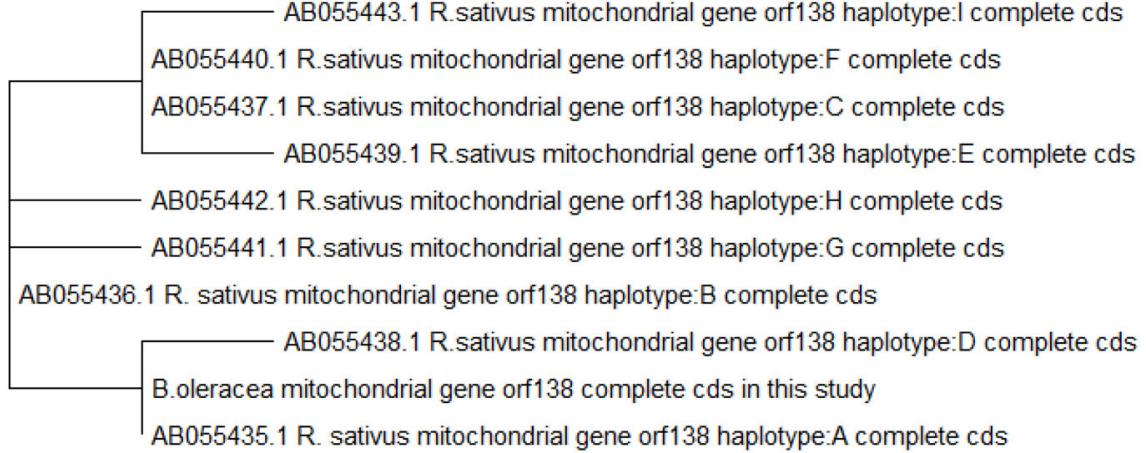

0.0010

Fig. 4 Ogura CMS Unique regions homologous to mitochondrial genomes of and evolutionary analysis of Ogura CMS orf138. Alignment of the Ogura CMS Unique region I (A) and Ogura CMS Unique region II (B) to the mitochondrial genomes of the maintainer line, Raphanus sativus (Ogura-type) and Raphanus sativus (normal-type). The query sequences are the Ogura CMS Unique region I (6291 bp) and Unique region II (7056 bp). orf138a is located at the edge of Unique region (I) orf154a is at the edge of Unique region (II) Different colored boxes indicate the sequence alignment scores to the three mitochondrial genomes. (C) Evolutionary analysis of Ogura CMS cabbage orf138 with nine haplotypes from radish using the Maximum Likelihood method. The tree was drawn to scale, with branch lengths measured as the number of substitutions per site. The accession numbers of the orf138 sequences are shown in the tree 
Table 1 The specific open reading frames (ORFs) in the Ogura CMS mitochondrial genome

\begin{tabular}{lll}
\hline Specific open-reading frames (orf) & $\begin{array}{l}\text { the most similar mitochondrial } \\
\text { sequence of other species }\end{array}$ & location in the Ogura CMS line \\
\hline orf102a & $\begin{array}{l}\text { YP_717109.1 hypothetical protein } \\
\text { BrnapMp010 [Brassica napus] } \\
\text { AEX57663.1 hypothetical protein } \\
\text { orf122b }\end{array}$ & In the Ogura-CMS Unique region II \\
orf138a & YP_006665998.1 hypothetical \\
& protein [Raphanus sativus] & In the Ogura-CMS Unique region II \\
orf154a & AEX57662.1 hypothetical protein & In the Ogura-CMS Unique region I \\
& RasatMp031 [Raphanus sativus] & Between Ogura-CMS block 4 and \\
\hline
\end{tabular}

Four ORFs, including ORF102a, ORF122b, ORF138a, and ORF154a, were specifically identified in the Ogura CMS mitochondrial genome. ORF102a is closest to the mitochondrial protein of Brassica napus. ORF122b, ORF138a and ORF154a were most similar to the mitochondrial sequence of Raphanus sativus. ORF102a and ORF122b were located in the Ogura CMS unique region II and ORF138a was located at the left edge of the Ogura CMS unique region I; however, ORF154a was located between Ogura CMS block 4 and unique region II

4 and unique region II (Table 1; Fig. 4B). The orf138 sequences of Ogura CMS were classified into nine haplotypes from A to I [24]. We found that orf138a in our Ogura CMS cabbage line belongs to the haplotype A by nucleotide alignment and evolutionary analysis (Supplementary Fig. 2 and Fig. 4 C). Haplotype A sequence only appears in radish cultivar 'MS-Gensuke'. Taken together, the original cytoplasm donor cabbage material was most likely generated by recombination with Ogura-type radish cultivar 'MS-Gensuke' through intergeneric hybridizations or cell fusion during the breeding process.

\section{Identification of CMS-associated ORFs in the Ogura CMS mitochondrial genomes}

To reveal the genes determining the CMS phenomenon, we compared the mitochondrial genomes between the maintainer and Ogura CMS lines. Four ORFs that encoded over 100 amino acids, including ORF102a, ORF122b, ORF138a and ORF154a, were specifically identified in the Ogura CMS mitochondrial genome (Table 1). These specific genes in the unique region were generated by recombination, which is generally considered to control the CMS trait. We also found that ORF122b, ORF138a and ORF154a were identical to mitochondrial proteins of radish cultivar MS-Gensuke. To further verify whether these ORFs were candidate proteins for CMS, the structure of these three proteins were predicted. We found that ORF138a has only one transmembrane domain ; however, ORF154a possesses two transmembrane domains at the C-terminus of the protein, whereas ORF102a and ORF122b lack transmembrane domains (Fig. 5). In addition, orf154a was located between Ogura CMS block 4 and Unique region II of mitochondrial genome of Ogura CMS lines. orf154a has partial homologous sequences to the ATP synthase subunit 1 (atpA) gene. orf138a is co-transcribed with atp8, which was confirmed using reverse transcription polymerase chain reaction (RTPCR) (Fig. 6). In conclusion, our data indicated that both orf138a and orf154a were likely responsible for Ogura CMS.

\section{Detection of ATP production in the Ogura CMS cabbage lines}

From our whole mitochondrial genome data, we found that the orf138a was co-transcribed with atp8, and orf $154 a$ has partial homology to the atp $A$ gene; therefore, we wondered whether the functions of orf $138 a$ and orf $154 a$ are associated with the yield of ATP. To answer this question, we measured the ATP content in anther samples from maintainer and Ogura CMS cabbage lines. We found that the ATP level in the anther samples of Ogura CMS cabbage lines was remarkably higher than that in the maintainer lines (Fig. $7 \mathrm{~A}$ ). The change in ATP yield may cause by altered ATPase activity. To test this hypothesis, ATPase activity was detected in maintainer and Ogura CMS cabbage lines. As expected, slightly higher ATPase activity was detected in the anther samples of Ogura CMS cabbage lines compared with that in the maintainer lines (Fig. 7B). In conclusion, the alterations in ATPase activity and ATP content indicate that orf138a and orf154a might influence the mitochondrial energy metabolic pathways.

\section{Paraffin section analysis of anther development in the maintainer and Ogura CMS cabbage lines}

From our mitochondrial sequence data, the cabbage Ogura CMS possesses the orf138a gene from radish, which is thought to be responsible for the male-sterile phenotype in most CMS systems. However, the vegetative growth of these two lines is not different. Meanwhile, the mechanism of male sterility gene on pollen abortion is still uncertain. Consequently, we performed comparative cytological analysis of anther development in the maintainer and Ogura CMS cabbage lines to demonstrate which cell types were affected in the stamens of the Ogura CMS line, and to further determine the cause of Ogura CMS of cabbage. In the maintainer line, the stamen meristem differentiates into the anther primordia with four microsporangiums; then the archesporial cells in each microsporangium differentiates into secondary parietal 
A

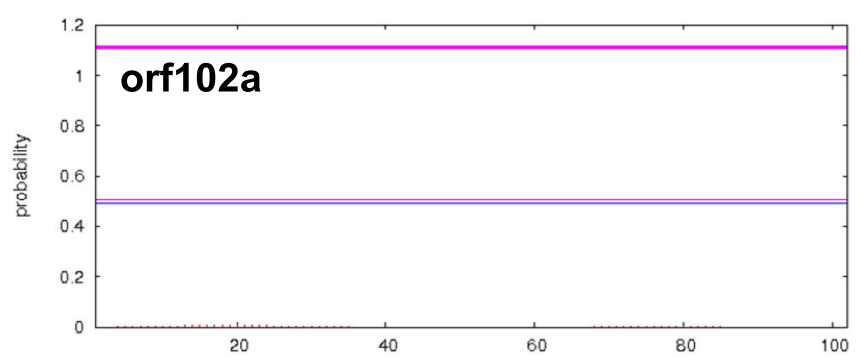

B

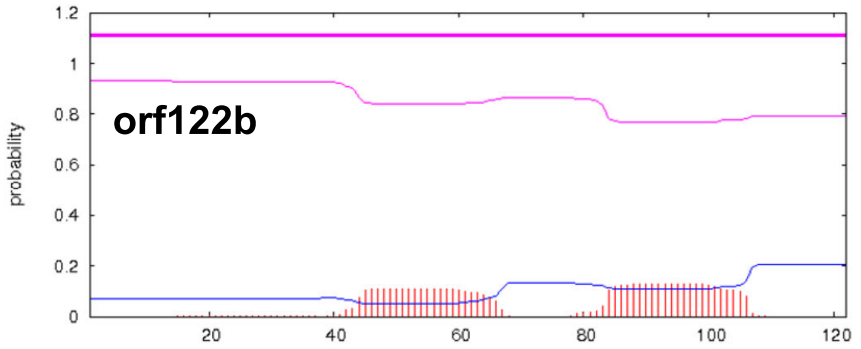

C

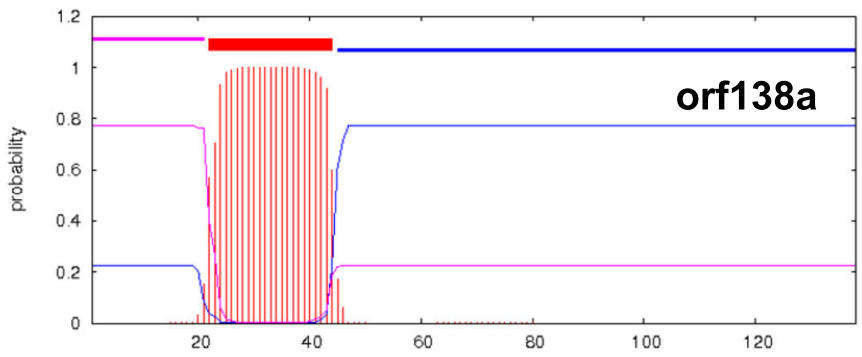

D

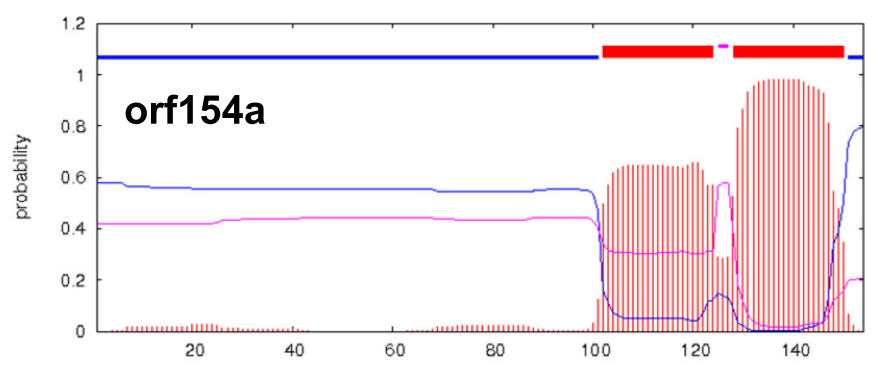

transmembrane

inside

outside

Fig. 5 Transmembrane domain prediction of candidate CMS genes encoded proteins in the Ogura CMS line. The output of the TMHMM server shows the location and probability associated with the predicted transmembrane domains in the Ogura CMS line, (A) ORF102a, (B) ORF122b, (C) ORF138a, and (D) ORF154a

cell layers and sporogenous cells (Fig. 8 A). Then, the microspore mother cells, tapetum, middle layer, endothecium and epidermis are generated after asymmetric and symmetrical cell divisions (Fig. 8B). The tetrads containing microspores enclosed by the callose wall are formed after meiosis II (Fig. 8 C). Free haploid microspores are released from the tetrads during the uninucleate microspore stage (Fig. 8D). The mature pollen grain is then generated, and the tapetal cells begin to separate from the middle layer (Fig. 8E). At last stage, the tapetum completely disappears and anther dehiscence occurs with the release of mature pollen grains (Fig. 8 F). However, in the Ogura CMS line, everything seemed normal at sporogenesis cell stage (Fig. 8G), haploid microspores can be formed and released properly (Fig. 8I J); however, tapetal cells began to show abnormal activity at the end of the meiosis II stage, becoming thicker (Fig. $8 \mathrm{H}, 8 \mathrm{I}$ and $8 \mathrm{~J})$. Expanded tapetal cells hindered the development of haploid microspores through spatial oppression, 


\section{A

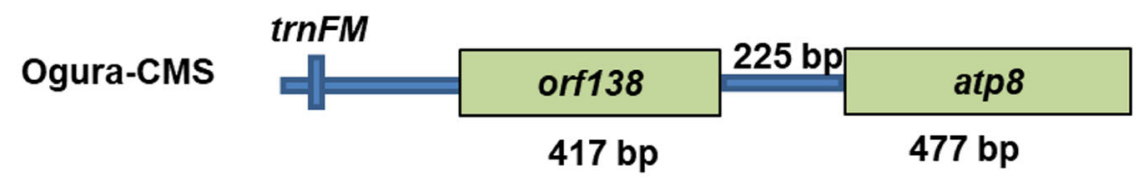

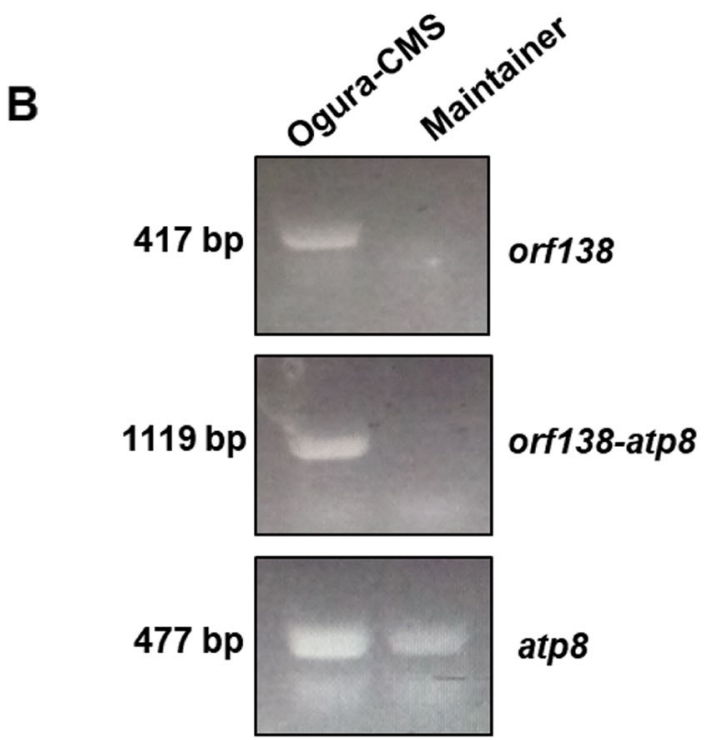

Fig. 6 Co-transcription of orf138a and atp8 in the Ogura CMS line. (A) Co-transcription structure of orf138a and atp8. (B)Transcription of orf138a/atp8 and co-transcription detection of orf138a and atp8 were detected in the maintainer and Ogura CMS lines. The CDNA of Ogura CMS and maintainer lines derive from the same experiment and the gels were processed in parallel.The full-length gel is provided in Supplementary Figure 1

which resulted in the structural disruption of haploid microspores. Finally, both haploid microspores and tapetal cells degenerate quickly (Fig. $8 \mathrm{~K}$ and $8 \mathrm{~L}$ ). Taken together, the abnormal proliferation of tapetal cells might be the immediate cause of cytoplasmic male-sterility in Ogura CMS cabbage lines.

\section{Comparative RNA-seq-based transcriptional profiling of maintainer and Ogura CMS lines}

To further understand the molecular mechanisms underlying Ogura CMS, whole genome transcriptional profiling between the maintainer and Ogura CMS lines was investigated using RNA-seq analysis. According to the Gene Ontology (GO)enrichment analysis of differentially expressed genes (DEGs) between the two lines, we found that the DEGs were significantly enriched in starch and sucrose metabolism (ko00500), biosynthesis of secondary metabolites (ID: ko01040) and metabolic pathway (ID: ko01100) (Fig. 9 A). These results indicated that the presence of orf138 impacts energy metabolism pathways. To identify the metabolic pathway in which the DEGs are involved, we performed Heatmap analysis based on the 'fragments per kilobase of exon per million mapped reads' (FPKM) method (Fig. 9B and Supplementary Table 4). Interestingly, the Bol016401 gene encoding cytochrome bd ubiquinol oxidase was up-regulated in the Ogura CMS lines, which is involved in the production of ATP in the mitochondrial electron transport chain (ETC). In addition, Bol036210 (SQP1, FAD/NAD (P)-binding oxidoreductase family protein) functions in the ETC, based on its activity as a monooxygenase. Furthermore, Bol033832 (NAD (P)-linked oxidoreductase superfamily protein) and Bol027393 (HSR8, NAD (P)binding Rossmann-fold superfamily protein) participate in the ETC according to their oxidoreductase activities. The RNA-seq results showed that presence of orf138a and orf154a in the Ogura CMS might influence the transcript levels of genes in energy metabolic pathways.

\section{Discussion}

Original Ogura CMS cabbage mitochondrial genome was generated by recombination with Ogura type radish There are three origins of Brassicaceae CMS, including intraspecific variations, alloplasmic origin by interspecific or 

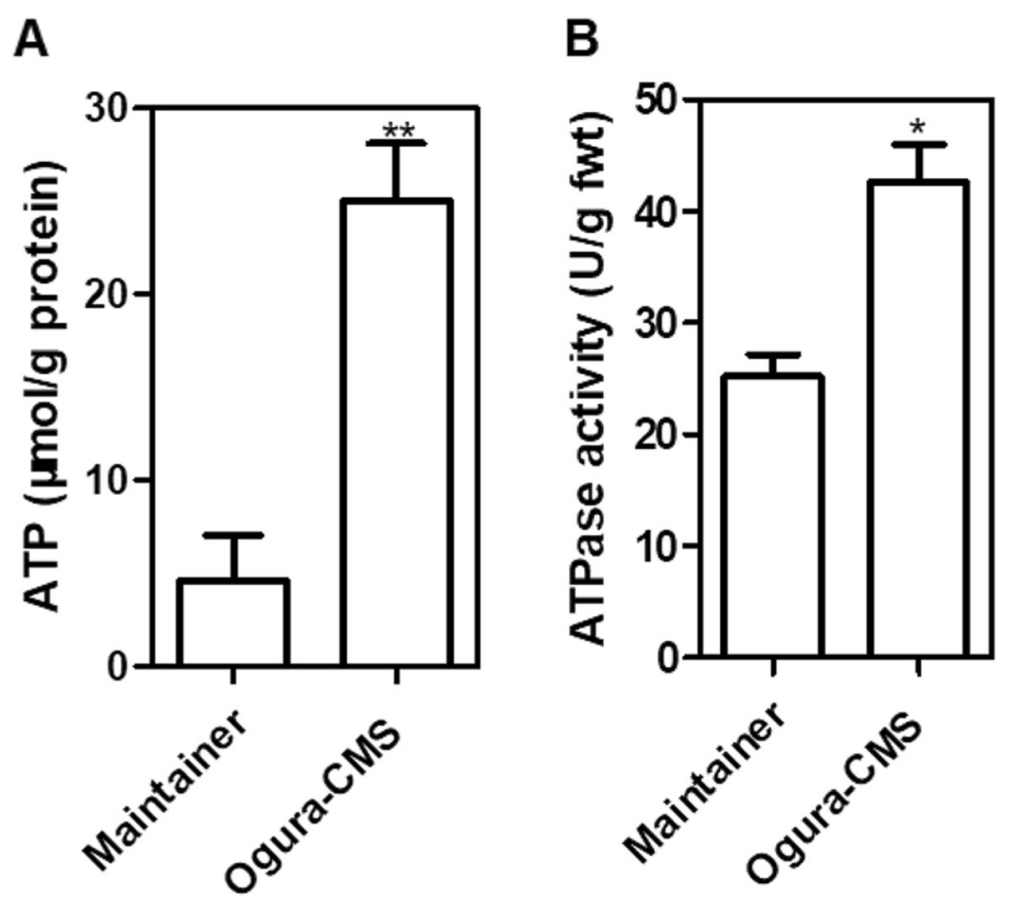

Fig. 7 The production of ATP and ATP synthase activity in petal samples of maintainer and Ogura CMS cabbage lines. (A) Analyses of the ATP content in petal of maintainer and Ogura CMS cabbage lines. (B) Analyses of the ATP synthase activity in petal of maintainer and Ogura CMS cabbage lines. Shown are t-test comparison statistics (means $\pm S D ; n=3$ ). ${ }^{*} P<0.05 ;{ }^{* *} P<0.01 ;{ }^{* * *} P<0.001$

intergeneric hybridizations, and cell fusion [25]. The pol CMS, 681 A CMS of B. napus and hau CMS in B. juncea are three examples of spontaneous male sterility [8, 26, 27], which were caused by intraspecific variations. Some CMS lines in $B$. oleracea were obtained by sexual hybridization with B. rapa, B. nigra, B. napus, $R$. sativus (Early scarlet Globe) and $R$. sativus (Ogura) [4]. R. sativus (Ogura) was usually used to produce CMS plants by cell fusion, generating the CMS lines with abortion in the tetrad stage [28]. In the present study, the complete mitochondrial genomes of maintainer and Ogura CMS cabbage were constructed through sequencing and de novo assembly. Syntenic regions analysis of the mitochondrial genomes between these two cabbage lines showed that the Ogura CMS cabbage mitochondrial genome has five unique regions (Fig. $3 \mathrm{~A}$ ). These regions are non-homologous to maintainer cabbage mitochondrial genome, but are identical to the sequence reported for radish Ogura-type mitochondrial genomes (AB694744) (Fig. 4). In conclusion, the original cytoplasm donor cabbage material was recombined from normal cabbage and Ogura CMS radish (MS-Gensuke) by intergeneric hybridizations or cell fusion.

\section{Candidate genes controlling the Ogura CMS of cabbage}

Candidate genes were selected for the CMS-associated genes based on the following characteristics: Novel chimeric structure, transmembrane domains and cotranscription events. For instance, orf138, orf300a, orf463, orf 222 and orf 224 have been confirmed to be generated by recombination of mitochondrial genome, possessing above mentioned characters, and are responsible for the Ogura CMS in Brassica [9], CMS in pepper [29], Dongbu cytoplasmic and genic male-sterility (DCGMS) CMS in radish [28], and nap and pol CMS in Brassica napus $[1,11]$, respectively. In the present study, ORF102a, ORF122b, ORF138a and ORF154a were specific ORFs in the Ogura CMS cabbage mitochondria, but only ORF138a and ORF154a were transmembrane proteins. orf $154 a$ has partial homologous sequences to the ATP synthase subunit 1 (atpA) gene. Furthermore, orf138a is co-transcribed with atp8 (Fig. 6). According to the energy deficiency model, CMS-associated ORF genes might disturb ATP synthesis [14]. For instance, ORFH79 can impair ATP production through binding to complex III and decreasing its enzyme activity, which results in abnormal pollen development in Honglian CMS rice [30]. The CMS associated gene orf188 promotes ATP production during mitochondrial oxidative phosphorylation [31]. Here, we found that the ATPase activity and ATP content were higher in the anther samples of the Ogura CMS cabbage line (Fig. 7), which means that orf138a and orf154a might affect the mitochondrial energy metabolic pathways. It was reported that alterations of mitochondria-encoded subunits of the $\mathrm{F}_{0} \mathrm{~F}_{1}$-ATP synthase triggered CMS in plants because of the high ATP demand of floral tissues [32, 33]. Furthermore, our 

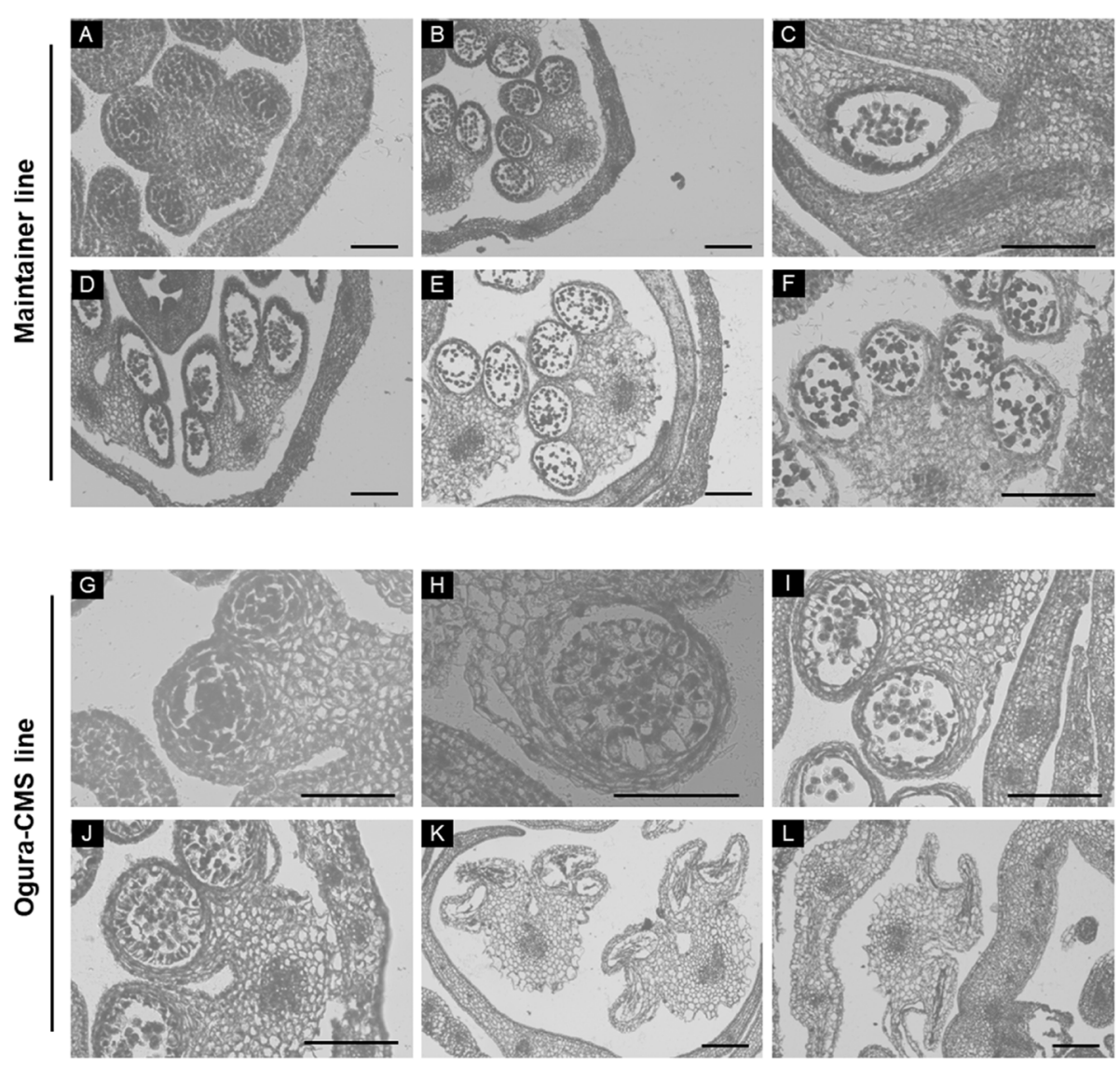

Fig. 8 Cytology of anther development of maintainer and Ogura CMS cabbage lines. (A) and (G) show the sporogenesis cell stage; (B) and (H) show the microspore mother cell stage; $(\mathbf{C})$ and $(\mathbf{I})$ show the tetrad stage; (D) and (J) show the uninucleate microspore stage; (E) and (K) show the mature pollen stage; $(\mathbf{F})$ and $(\mathbf{L})$ show the dehiscence stage. Scale bar $=50 \mu \mathrm{m}$

RNA-seq results confirmed that orf138a and orf154a in the Ogura CMS might affect the transcript levels of genes in energy metabolic pathways, especially those in the ETC (Fig. 9). Moreover, rps7 was lost in Ogura CMS cabbage because of the Unique region II insertion from radish. In a few cases, any disruption of the electron transport chain could impair energy production [34, 35]. Taken together, the disordered energy production in mitochondria triggers male sterility, which supports the mitochondrial energy deficiency model. In addition, orf138 is usually considered as the main candidate gene for the Ogura CMS. Actually, four genes orf102a, orf122b, orf138a, and orf154a, from other species were identified in our whole mitochondrial genome date. More functional analysis of orf138a and orf154a are required to understand the sterility mechanism in Ogura CMS of cabbage.

\section{Abnormal proliferation of tapetal cells probably causes male sterility in Ogura CMS cabbage}

The abortive stages of anther development in many CMSs of Brassica plants have been analyzed by cytological analysis. For example, premature cell death events of the tapetal cells impairs pollen development at the vacuolate microspore stage, leading to male sterility in Ogu-INRA CMS of rapeseed (Brassica napus) [36]. The abortion of anther development in the recessive male sterility cabbage $(83,121 \mathrm{~A})$ is caused by a lack of sporopollenin deposition and exine formation [37]. The dominant male sterility gene $M s-c d 1$ was found to suppress the expression of certain genes in tapetal cells, which might prevent the degradation of callose and pollen mother cell (PMC) wall in B. oleracea [38]. Our cytological sections data showed that the abnormal proliferation of tapetal cells hindered the development of haploid microspores through spatial constriction, which resulted in the structural disruption of haploid microspores in the Ogura CMS cabbage lines (Fig. $8 \mathrm{~K}$ and $8 \mathrm{~L}$ ). The RNA-seq results showed the transcription of genes in energy metabolic pathways was activated (Fig. 9), and the ATPase activity and ATP content were increased in the Ogura CMS lines (Fig. 7), which could provide the more energy for the abnormal proliferation of tapetal cells. Taken together, tapetal cells play an important role in the anther development. The abnormal 
A

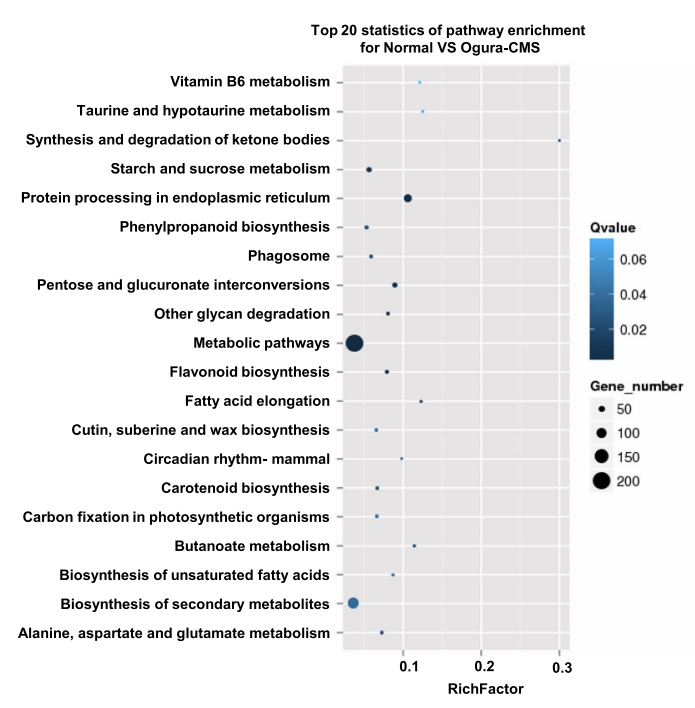

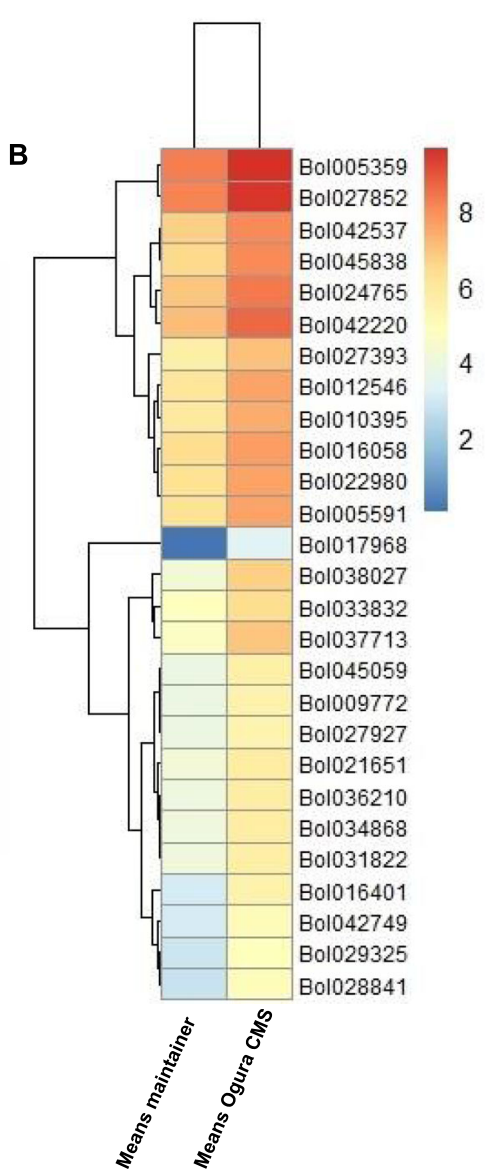

Fig. 9 Presence of orf138a leads to major transcriptional changes of genes in metabolic pathways. (A) Statistics of the top 20 pathway classifications from GO enrichment analysis of genes differentially expressed in maintainer and Ogura CMS cabbage lines (based on RNA-seq analyses). The number of genes and Q-values are indicated by the size of circles and the color of the rectangles, respectively. (B) Heatmap showing that the relative expression of the 27 differentially expressed metabolic and biosynthesis of secondary metabolites-related genes based on the FPKM method

PCD of tapetal cells might be the immediate cause of cytoplasmic male-sterility in our Ogura CMS cabbage lines.

\section{Conclusions}

We found that Ogura CMS cabbage lines consist of six syntenic regions from collinearity analysis of the mitochondrial genomes. ORF122b, ORF138a and ORF154a were highly similar to mitochondrial proteins of Raphanus sativus. Thus, our cabbage Ogura CMS line was probably generated through intergeneric hybridizations or cell fusion between cabbage and radish. Among these ORFs, orf $138 a$ and orf $154 a$ possessed the transmembrane structure, and orf138a was co-transcribed with atp8 and trnfM, orf154a has partial homologous sequences to the atpA gene. The ATPase activity and ATP content were higher in the in anther samples of Ogura CMS cabbage lines, suggesting that orf138a and orf154a affect ATP production in the mitochondrial energy metabolic pathways. The RNA-seq data also confirmed that the transcript levels of genes in the metabolic pathways were increased in the Ogura CMS lines. In addition, cytological sections showed that the abnormal proliferation of tapetal cells might be the immediate cause of cytoplasmic male-sterility in Ogura CMS cabbage lines. Taken together, orf138a and orf 154a lead to increased ATPase activity and ATP content by affecting the transcriptional levels of genes in energy metabolic pathways, which could provide the more energy for the abnormal proliferation of tapetal cells.

\section{Methods}

\section{Plant materials}

R2P2 is an open-pollination and early maturing cabbage variety. The original cytoplasm donor cabbage material was introduced from Germany in 2004 by Dr. Yuancai Jian from the Beijing Vegetable Research Center of Beijing Academy of Agriculture and Forestry Sciences (BAAFS). It was confirmed as a male sterile material with the Ogura cytoplasm containing orf138. R2P2 was crossed with donor cabbage material and backcrossed 
for eight generations to generate the BC8 CMS cabbage line R2P2CMS, with R2P2 as the paternal line in all crosses. The stability of R2P2CMS was observed for more than 10 years in two experimental fields of the Beijing Vegetable Research Center (BVRC). The mitochondrial DNA of Ogura CMS (R2P2CMS) and maintainer (R2P2) lines were sent to Biozeron Company (Shanghai, China) for DNA library construction and sequencing. R2P2CMS and R2P2 lines were grown under the same conditions. After flowering, six inflorescences (with the same size) from several CMS plants and six inflorescences from several maintainer plants were harvested, respectively. In each line, six inflorescences were further randomly assigned to two subgroups. These four subgroup samples, named R2P2CMS-1, R2P2CMS-2, R2P2-1, and R2P2-2, were stored in liquid nitrogen and then at $-80^{\circ} \mathrm{C}$ for RNA-seq analysis.

\section{Mitochondrial genomes sequencing and assembling}

About $5 \mathrm{~g}$ of fresh cabbage leaves was harvested for mtDNA isolation using a modified extraction method [39]. One microgram of purified mtDNA was fragmented to generate $430 \mathrm{bp}$ short-insert libraries following the manufacturer's instructions (Illumina, San Diego, CA, USA), and sequenced on the Illumina Hiseq 4000 platform [40]. The high molecular weight DNA was purified for PacBio library prep, BluePippin size selection, and sequenced on the Pacbio Sequel Sequencer (PacBio Inc., Menlo Park, CA, USA). Then, the adapters, reads containing over $10 \%$ Ns (uncalled bases), duplicated sequences and low-quality reads (the Phred scores $<$ Q20) were removed. The Phred scores $(\mathrm{Q} 20$, Q30) and GC content of the clean data were calculated. The mitochondria genome framework was constructed using both Illumina Hiseq and Pacbio Sequel data using ABySS v2.0.2 and SPAdes v3.10.1 software [41]. The contig gaps were filled to complete the circular or linear mitochondria genomes of maintainer and Ogura CMS cabbage lines. The circular genome maps were drawn using OrganellarGenomeDRAW v1.2 [42].

\section{Reverse transcription-PCR}

Total RNA was isolated from the anthers of maintainer and Ogura CMS lines using TRIzol ${ }^{\circ}$ Reagent (Invitrogen Waltham, MA, USA), and first-strand cDNA was synthesized from total RNA using a reverse transcriptase (Takara, Dalian, China). RT-PCR amplification was performed with the following thermal cycles: An initial denaturation step at $94{ }^{\circ} \mathrm{C}$ for $5 \mathrm{~min} ; 35$ cycles of $94{ }^{\circ} \mathrm{C}$ for $10 \mathrm{~s}, 55^{\circ} \mathrm{C}$ for $1 \mathrm{~min}$, and $72{ }^{\circ} \mathrm{C}$ for $1 \mathrm{~min}$; and a final 10 -min extension at $72{ }^{\circ} \mathrm{C}$. Primers for the RT-PCR assays are shown in Supplementary Table 3.

\section{Genome annotation}

The mitochondria genes were annotated using combination of homology alignment and de novo prediction. Opening reading frames (ORFs) in the mitochondrial genome were identified using ORF Finder (http://www. ncbi.nlm.nih.gov/gorf/gorf.html). Ribosome RNA (rRNA) and transfer RNA (tRNA) genes were predicted using rRNAmmer 1.2 and tRNAscan-SE, respectively [43, 44]. A whole mitochondria genome blast search was performed against the following databases: KEGG (Kyoto Encyclopedia of Genes and Genomes) [45], COG (Clusters of Orthologous Groups) [46], NR (Non-Redundant Protein Database database), Swiss-Prot [47], and GO (Gene Ontology) [48]. Transmembrane domains in each candidate ORF were assessed using TMHMM Server v.2.0 (http://www.cbs.dtu. $\mathrm{dk} /$ services/TMHMM/).

\section{ATP content and synthase activity measurement}

The anthers of maintainer and Ogura CMS lines were harvested for ATP content and synthase activity quantification. The ATP content and synthase activity were measured using an ATP content assay kit and an $\mathrm{Na}^{+} \mathrm{K}^{+}$-ATP synthase activity assay kit by detecting luciferase signals using a multifunctional microplate reader at $340 \mathrm{~nm}$ and $660 \mathrm{~nm}$, respectively (Solarbio Co., Ltd., Beijing, China). The detailed procedures were carried out according to the manufacturer's instructions ((Solarbio, BC0300 and BC0065).

\section{Cytological analysis}

Preparation and observation of ultra-thin sections: The anthers of maintainer and Ogura CMS lines were fixed in formalin-aceto-alcohol (FAA) solution. The samples were dehydrated with a graded ethanol series $(30,50,70$, $80,90,95$, and $100 \%$ ) after rinsing with distilled water. The anthers were embedded in Spur (ERL-4206) and sectioned into $3 \mathrm{~mm}^{2}$ sections (approximately $2000 \mathrm{~nm}$ thick) using a Leica ultracut $\mathrm{R}$ ultramicrotome (Leica Wetzlar, Germany). The samples were dried overnight in a $70{ }^{\circ} \mathrm{C}$ incubator, and then stained with $1 \%$ toluidine blue or $0.5 \%$ crystal violet stain solution. A Leica DMR2 microscope was used to observe the cell structure of anther; the images were photographed using a Nikon Coolpix4200 camera (Nikon, Tokyo, Japan). Preparation and observation of sample for transmission electron microscopy (TEM): Fresh anthers of maintainer and Ogura CMS lines were fixed overnight in $2 \%$ glutaraldehyde. The samples were dehydrated with a graded ethanol series $(30,50,70,80,90,95$, and $100 \%)$ after rinsing with distilled water. The anthers were embedded in epoxy resin 618 (Bluestar Wuxi Petrochemical Co., Ltd, China) and sectioned into $3 \mathrm{~mm}^{2}$ sections (approximately $2000 \mathrm{~nm}$ thick) using a Leica ultracut R ultramicrotome. The samples were stained with uranyl acetate 
and lead nitrate solution. The images were photographed using a Hitachi H-7500 transmission electron microscope (Hitachi, Tokyo, Japan).

\section{Illumina sequencing and transcriptome analysis}

Total RNA was extracted from the inflorescence of Ogura CMS and its maintainer line using an RNAprep Pure Plant Kit (Tiangen Co., Ltd., Beijing, China) following the manufacturer's protocol. High-quality RNA from each sample was used for cDNA library construction and RNA-Seq on the Illumina HiSeqTM 2000 platform at the Beijing Genomics Institute (BGI, Beijing, China). The clean reads were obtained by filtering the adaptor reads, low quality reads ( $>50 \%$ bases had Q-values $\leq 5$ ) and unidentified bases ("N" reads $>10 \%$ ). The clean reads were mapped to the $B$. oleracea genome using the TopHat2 package (2.0.10) [49]. Gene Ontology (GO) classification for understanding the distribution of gene function was conducted by using WEGO software [50]. Pathways with Q-value $<0.05$ were considered as significantly enriched for the DEGs. The abundance of differentially expressed transcripts related to metabolism and biosynthesis of secondary metabolite was estimated by calculating read density as 'fragments per kilobase of exon per million mapped reads' (FPKM) using Cuffdiff (v2.1.1) [51].

\section{Abbreviations \\ CMS: Cytoplasmic male sterility; mtDNA: Mitochondrial DNA; ORF: Open reading frame; ORF: Open reading frame; ATP1, ATP4, ATP6, ATP8, and ATP9: ATP synthase subunits 1, 4, 6, 8, and 9 genes; COB: Apocytochrome $b$ gene; COX1-3: Cytochrome c oxidase subunits 1-3 genes; NAD1-7, 9 and NAD4L: NADH dehydrogenase subunits $1-7,9$, and $4 L$ genes; RPL2, RPL5, RPL16, RPS4, RPS7, RPS12 and RPS14: ribosomal protein large subunit genes; tRNA: Transfer RNA (tRNA) genes}

\section{Supplementary Information}

The online version contains supplementary material available at https://doi. org/10.1186/s12864-021-07963-x.

\section{Additional file 1. \\ Additional file 2. \\ Additional file 3. \\ Additional file 4. \\ Additional file 5. \\ Additional file 6 .}

\section{Acknowledgements}

We thank Dr. Peirong Li from Beijing Vegetable Research Center, Beijing Academy of Agriculture and Forestry Sciences, for his helpful analysis of RNA-seq data.

\section{Authors' contributions}

$X Z$ carried out the sequence data analysis, and drafted the manuscript. XZ, $\mathrm{DC}, J \mathrm{C}, \mathrm{HL}$, and $\mathrm{YH}$ designed and coordinated all experiments. HL prepared plant materials. JK supervised the work and edited the manuscript. All authors read and approved the final manuscript.

\section{Funding}

This study was supported by the National Natural Science Foundation of China (31972408), the Science and Technology Innovation Capacity Building Projects of the Beijing Academy of Agriculture and Forestry Sciences (KJCX20200410, KJCX20210425 and KJCX20200113), and Innovation and Development Program of Beijing Vegetable Research Center (KYCX202106).

\section{Availability of data and materials}

The datasets supporting the conclusions of this article are available in the GenBank nucleotide sequence database repository [MW423604 and MW423605; https://www.ncbi.nlm.nih.gov/genbank/].

\section{Declarations}

Ethics approval and consent to participate

Our plant materials don't include any wild species at risk of extinction. No specific permits are required for sample collection in this study. We comply with relevant institutional, national, and international guidelines and legislation for plant study.

\section{Competing interests}

The authors declare they have no competing interests.

\section{Author details}

'Beijing Vegetable Research Center, Beijing Academy of Agriculture and Forestry Sciences, Key Laboratory of Biology and Genetic Improvement of Horticultural Crops (North China), Ministry of Agriculture, 100097 Beijing, P.R. China. ${ }^{2}$ College of Horticulture, Gansu Agricultural University, 730070 Lanzhou, P.R. China.

Received: 23 December 2020 Accepted: 27 August 2021

Published online: 07 September 2021

\section{References}

1. Singh M, Brown G. Suppression of cytoplasmic male sterility by nuclear genes alters expression of a novel mitochondrial gene region. The Plant Cell 1991:3:1349-1362.

2. Vedel F, Pla M, Vitart V, Gutierres S, Chetrit P, De Paepe R. Molecular basis of nuclear and cytoplasmic male sterility in higher plants. Plant Physiology and Biochemistry 1994;32:601-608.

3. Ogura H. Studies on the New Male-Sterility in Japanese Radish, with Special Reference to the Utilization of this Sterility towerds the Practical Raising of Hybrid Seeds. Memoirs of the Faculty of Agriculture, Kagoshima University 1967:6:39-78.

4. Bannerot $H$ BL, Couderon Y, Temple J. Transfer of cytoplasmic male sterility from Raphanus sativus to Brassica oleracea. In: In: Wills AB, North C (Eds) Proc Eucarpia Meet Cruciferae. Scottish Hortic Res Inst, Invergavrie, UK; 1974: 52-54.

5. Shiga T, Baba S. Cytoplasmic male sterility in rape plants (Brassica napus L). Japanese Journal of Breeding 1971:21:16-17.

6. Shiga T, Baba S. Cytoplasmic Male Sterility in Oil Seed Rape. Brassica napus L., and its Utilization to Breeding. Japanese Journal of Breeding 1973;23: 187-197.

7. Yarrow SA, Burnett LA, Wildeman RP, Kemble RJ. The transfer of 'Polima' cytoplasmic male sterility from oilseed rape (Brassica napus) to broccoli (B. oleracea) by protoplast fusion. Plant Cell Reports 1990;9:185-188.

8. Wan Z, Jing B, Tu J, Ma C, Shen J, Yi B et al. Genetic characterization of a new cytoplasmic male sterility system (hau) in Brassica juncea and its transfer to B. napus. Theoretical and Applied Genetics 2008;116:355-362.

9. Grelon M, Budar F, Bonhomme S, Pelletier G. Ogura cytoplasmic malesterility (CMS)-associated orf138 is translated into a mitochondrial membrane polypeptide in male-sterile Brassica cybrids. Molecular Genetics and Genomics 1994;243:540-547.

10. Tanaka Y, Tsuda M, Yasumoto K, Yamagishi H, Terachi T. A complete mitochondrial genome sequence of Ogura-type male-sterile cytoplasm and its comparative analysis with that of normal cytoplasm in radish (Raphanus sativus L.). BMC Genomics 2012;13:352.

11. Lhomme Y, Stahl R, Li X, Hameed A, Brown G. Brassica nap cytoplasmic male sterility is associated with expression of a mtDNA region containing a chimeric gene similar to the pol CMS-associated orf224 gene. Current Genetics 1997;31:325-335. 
12. Heng S, Wei C, Jing B, Wan Z, Wen J, Yi B et al. Comparative analysis of mitochondrial genomes between the hau cytoplasmic male sterility (CMS) line and its iso-nuclear maintainer line in Brassica juncea to reveal the origin of the CMS-associated gene orf288. BMC Genomics 2014;15:322.

13. Jing B, Heng S, Tong D, Wan Z, Fu T, Tu J et al. A male sterility-associated cytotoxic protein ORF288 in Brassica juncea causes aborted pollen development. Journal of Experimental Botany 2012;63:1285-1295.

14. Chen L, Liu Y. Male Sterility and Fertility Restoration in Crops. Annual Review of Plant Biology 2014;65:579-606.

15. Duroc Y, Gaillard C, Hiard S, Defrance M, Pelletier G, Budar F. Biochemical and functional characterization of ORF138, a mitochondrial protein responsible for Ogura cytoplasmic male sterility in Brassiceae. Biochimie 2005;87:1089-1100.

16. Heng S, Gao J, Wei C, Chen F, Li X, Wen J et al. Transcript levels of orf288 are associated with the hau cytoplasmic male sterility system and altered nuclear gene expression in Brassica juncea. Journal of Experimental Botany 2018;69:455-466.

17. Wu H, Cheung AY. Programmed cell death in plant reproduction. Plant Molecular Biology 2000;44:267-281.

18. Kawanabe T, Ariizumi T, Kawaiyamada M, Uchimiya H, Toriyama K. Abolition of the Tapetum Suicide Program Ruins Microsporogenesis. Plant and Cell Physiology 2006;47:784-787.

19. Ji C, Li H, Chen L, Xie M, Wang F, Chen Y et al. A Novel Rice bHLH Transcription Factor, DTD, Acts Coordinately with TDR in Controlling Tapetum Function and Pollen Development. Molecular Plant 2013;6:17151718.

20. Papini A, Mosti S, Brighigna L. Programmed-cell-death events during tapetum development of angiosperms. Protoplasma 1999;207:213-221.

21. Zubko MK. Mitochondrial tuning fork in nuclear homeotic functions. Trends in Plant Science 2004:9:61-64.

22. Linke B, Nothnagel T, Börner T. Flower development in carrot CMS plants: mitochondria affect the expression of MADS box genes homologous to GLOBOSA and DEFICIENS. The Plant Journal 2003;34:27-37.

23. Fujii S, Toriyama K. Suppressed expression of RETROGRADE-REGULATED MALE STERILITY restores pollen fertility in cytoplasmic male sterile rice plants. Proceedings of the National Academy of Sciences of the United States of America 2009;106:9513-9518.

24. Yamagishi $H$, Terachi $T$. Intra- and inter-specific variations in the mitochondrial gene orf138 of Ogura-type male-sterile cytoplasm from Raphanus sativus and Raphanus raphanistrum. Theoretical and Applied Genetics 2001;103:725-732.

25. Yamagishi H, Bhat SR. Cytoplasmic male sterility in Brassicaceae crops. Breeding Science 2014;64:38-47.

26. Liu Z, Guan C, Zhao F, Chen S. Inheritance and mapping of a restorer gene for the rapeseed cytoplasmic male sterile line 681A. Plant Breeding 2005; 124:5-8.

27. Liu H, Fu T. and Yang X. Discovery and studies on Polima CMS line. In: Proc 7th Int Rapeseed Cong. Pozman, Poland; 1987: 69-78.

28. Park JY, Lee Y, Lee J, Choi B, Kim S, Yang T. Complete mitochondrial genome sequence and identification of a candidate gene responsible for cytoplasmic male sterility in radish (Raphanus sativus L.) containing DCGMS cytoplasm. Theoretical and Applied Genetics 2013;126:1763-1774.

29. Wang P, Lu Q, Ai Y, Wang Y, Li T, Wu L et al. Candidate Gene Selection for Cytoplasmic Male Sterility in Pepper (Capsicum annuum L.) through Whole Mitochondrial Genome Sequencing. International Journal of Molecular Sciences 2019;20:578.

30. Wang K, Gao F, Ji Y, Liu Y, Dan Z, Yang P et al. ORFH79 impairs mitochondrial function via interaction with a subunit of electron transport chain complex III in Honglian cytoplasmic male sterile rice. New Phytologist 2013;198:408-418.

31. Liu J, Hao W, Liu J, Fan S, Zhao W, Deng L et al. A Novel Chimeric Mitochondrial Gene Confers Cytoplasmic Effects on Seed Oil Content in Polyploid Rapeseed (Brassica napus). Molecular Plant 2019;12:582-596.

32. Xu P, Yang $Y$, Zhang Z, Chen W, Zhang C, Zhang $L$ et al. Expression of the nuclear gene TaFAd is under mitochondrial retrograde regulation in anthers of male sterile wheat plants with timopheevii cytoplasm. Journal of Experimental Botany 2008;59:1375-1381.

33. Millar AH, Whelan J, Soole KL, Day DA. Organization and regulation of mitochondrial respiration in plants. Annu Rev Plant Biol 2011;62:79-104.
34. Tang D, Wei F, Khan A, Munsif F, Zhou R. Degradation of mitochondrial structure and deficiency of complex I were associated with the transgenic CMS of rice. Biological research 2021;54:6.

35. Horn R, Gupta KJ, Colombo N. Mitochondrion role in molecular basis of cytoplasmic male sterility. Mitochondrion 2014;19:198-205.

36. Gonzalezmelendi P, Uyttewaal M, Morcillo CN, Mora JRH, Fajardo S, Budar F et al. A light and electron microscopy analysis of the events leading to male sterility in Ogu-INRA CMS of rapeseed (Brassica napus). Journal of Experimental Botany 2008;59:827-838.

37. Ji J, Yang L, Fang Z, Zhuang M, Zhang Y, Lv H et al. Recessive male sterility in cabbage (Brassica oleracea var. capitata) caused by loss of function of BoCYP704B1 due to the insertion of a LTR-retrotransposon. Theoretical and Applied Genetics 2017;130:1441-1451.

38. Kang J, Zhang G, Bonnema G, Fang Z, Wang X. Global analysis of gene expression in flower buds of Ms-cd1 Brassica oleracea conferring male sterility by using an Arabidopsis microarray. Plant Molecular Biology 2008;66: 177-192.

39. Chen J, Guan R, Chang S, Du T, Zhang H, Xing H. Substoichiometrically different mitotypes coexist in mitochondrial genomes of Brassica napus $\mathrm{L}$. PLOS ONE 2011;6:e17662.

40. Borgstrom E, Lundin S, Lundeberg J. Large scale library generation for high throughput sequencing. PLOS ONE 2011;6.

41. Antipov D, Korobeynikov A, Mclean JS, Pevzner PA. hybridSPAdes: an algorithm for hybrid assembly of short and long reads. Bioinformatics 2016; 32:1009-1015

42. Lohse M, Drechsel O, Bock R. OrganellarGenomeDRAW (OGDRAW): a tool for the easy generation of high-quality custom graphical maps of plastid and mitochondrial genomes. Current Genetics 2007:52:267-274.

43. Lagesen K, Hallin PF, Rodland EA, Staerfeldt H, Rognes T, Ussery DW. RNAmmer: consistent and rapid annotation of ribosomal RNA genes. Nucleic Acids Research 2007:35:3100-3108.

44. Lowe TM, Eddy SR. tRNAscan-SE: a program for improved detection of transfer RNA genes in genomic sequence. Nucleic Acids Research 1997;25: 955-964.

45. Kanehisa M, Goto S, Kawashima S, Okuno Y, Hattori M. The KEGG resource for deciphering the genome. Nucleic Acids Research 2004;32:D277-D280.

46. Tatusov RL, Fedorova ND, Jackson JD, Jacobs AR, Kiryutin B, Koonin EV et al. The COG database: an updated version includes eukaryotes. BMC Bioinformatics 2003;4:41.

47. Magrane M, Consortium U. UniProt Knowledgebase: a hub of integrated protein data. Database 2011:2011.

48. Ashburner M, Ball CA, Blake JA, Botstein D, Butler H, Cherry JM et al. Gene Ontology: tool for the unification of biology. Nature Genetics 2000;25:25-29.

49. Kim D, Pertea G, Trapnell C, Pimentel H, Kelley R, Salzberg SL. TopHat2: accurate alignment of transcriptomes in the presence of insertions, deletions and gene fusions. Genome Biol 2013;14:R36.

50. Ye J, Fang L, Zheng H, Zhang Y, Chen J, Zhang Z et al. WEGO: a web tool for plotting GO annotations. Nucleic acids research 2006;34:W293-297.

51. Trapnell C, Williams BA, Pertea G, Mortazavi A, Kwan G, van Baren MJ et al. Transcript assembly and quantification by RNA-Seq reveals unannotated transcripts and isoform switching during cell differentiation. Nature Biotechnology 2010;28:511-515.

\section{Publisher's Note}

Springer Nature remains neutral with regard to jurisdictional claims in published maps and institutional affiliations.

Ready to submit your research? Choose BMC and benefit from:

- fast, convenient online submission

- thorough peer review by experienced researchers in your field

- rapid publication on acceptance

- support for research data, including large and complex data types

- gold Open Access which fosters wider collaboration and increased citations

- maximum visibility for your research: over $100 \mathrm{M}$ website views per year

At $\mathrm{BMC}$, research is always in progress.

Learn more biomedcentral.com/submissions 